\title{
The outsourcing productivity paradox: total outsourcing, organisational innovation, and long run productivity growth
}

\section{Paul Windrum • Andreas Reinstaller • Christopher Bull}

Published online: 1 October 2008

(C) Springer-Verlag 2008

\begin{abstract}
A growing number of empirical studies find a relationship between the outsourcing of activities and a long term loss of firm productivity growth. The paper addresses this outsourcing productivity paradox by examining the connection between total outsourcing and organisational innovation. We present a model of organisational innovation in which managers raise productive efficiency by identifying organisational architectures that more effectively integrate value-adding activities and administrative routines. As part of this process, managers can internally or externally source an activity. Simulations of the model show that large scale outsourcing restricts the scope for future organisational innovation, leading to lower productivity growth. The findings accord with the empirical data and provide a salutary warning for managers and policy-makers about the long term implications of total outsourcing.
\end{abstract}

Keywords Outsourcing • Organisational innovation •

Long run productivity development

JEL Classifications D23 $\cdot$ D24 $\cdot$ D $83 \cdot$ O 33

P. Windrum $(\bowtie) \cdot$ C. Bull

Manchester Metropolitan University Business School, Aytoun Building,

Aytoun Street, Manchester, M1 3GH, UK

e-mail: p.windrum@mmu.ac.uk

C. Bull

e-mail: c.bull@mmu.ac.uk

P. Windrum

Max Planck Institute for Economics, Jena, Germany

A. Reinstaller

Austrian Institute for Economic Research (WIFO), P. O. Box 91, 1103, Vienna, Austria

e-mail: Andreas.Reinstaller@wifo.ac.at 


\section{Introduction}

Outsourcing involves the transfer of goods and services production, previously carried out internally, to an external provider (Domberger 1998). The term 'outsourcing' can cover many areas and activities, in manufacturing as well as services. While much of the media attention has tended to focus on foreign outsourcing by manufacturers and on call centres (so-called 'offshoring'), the vast majority of outsourcing is done 'locally' within the US and within Europe, and the vast majority of outsourcing is by services firms, not manufacturers (Willcocks and Plant 2003).

Recent empirical studies have highlighted the existence of an outsourcing productivity paradox (Görzig and Stephan 2002; Bengtsson and von Hartman 2005; Lacity and Willcocks 1998; Gianelle and Tattara 2007). In the shortrun, outsourcing firms are able to reduce costs. In the long-run, firms that engage in outsourcing suffer lower productivity growth than firms that do not engage in outsourcing. How is this paradox to be explained? In this paper we explore the impact of outsourcing on organisational innovation. Organisational innovation is a key source of long term productivity growth. The argument that organisational innovation drives economic growth is a central theme in Adam Smith's Wealth of Nations (Smith 1776) and, more recently, has been re-emphasised by Chandler (1980) and Harberger (1998). The central message of this paper is that it is not the ownership of activities that matters, per se, but how activities are controlled and integrated. Empirically, we know that the vast majority of outsourcing takes the form of 'total outsourcing' relationships. In this relationship the outsourcing firm has little or no control over the outsourced activity for long contractual periods. This severely limits the scope for ongoing organisational innovation and, hence, has a direct impact on long run productivity growth.

We explore the relationship between total outsourcing, organisational innovation, and long run productivity using a model of organisation innovation. In the model, organisational innovation is the search for new organisational architectures that more effectively bring together the externalities that exist between value-adding activities. Externalities exist between a set of related $\mathrm{R} \& \mathrm{D}$, design, production, and marketing activities within a firm (Langlois 2002), and between the activities of firms along the supply chain (Jacobides and Winter 2005). Organisational innovation involves experimentation with (a) different combinations of value-adding activities, and (b) the insourcing/outsourcing of activities. Over time, firms experiment with different organisational designs that recombine activities in new and novel ways, thereby raising the total factor productivity of its managerial, labour, and capital inputs. They also experiment with the sourcing of activities. A firm must identify and control core R\&D, design, production, and marketing activities for which there are strong externalities. Seen in this light, the make/buy decision is not a question of ownership but of control. What matters is the outsourcing relationship, and how this positively or negatively affects the firm's capacity to engage in future organisational change that reorganises activities (held 
in house or externally). Information technology is a key factor that affects the feasibility and the relative costs and benefits of outsourcing. The model therefore considers the effect on outsourcing strategies of new, internet-based IT systems that significantly lower the costs of external transaction costs.

The paper is organised as follows. Section 2 reviews the existing literature on the potential benefits and potential problems of outsourcing. This draws on research conducted in a number different discipline areas; transactions cost economics, strategic management, information systems, services innovation, and industrial organisation. These highlight a set of potential benefits that arise from cost reduction, specialisation, and substitution. In terms of potential costs, managers face problems in effectively monitoring contracts, with unforeseen transaction costs, in identifying core and non-core competences, and with estimating the externalities that exist between activities. Section 2 also reviews the empirical studies by Görzig and Stephan (2002), Bengtsson and von Hartman (2005), Lacity and Willcocks (1998), and Gianelle and Tattara (2007) on the relationship between outsourcing and long term productivity.

Section 3 examines the connection between total outsourcing, organisational innovation, and productivity growth. We introduce the key concepts of organisational architecture and organisational innovation, based on a modular theory of the firm. This theory is founded on the twin principles of increasing specialisation and the modularisation of complex organisational structures. Increasing the modularity of an organisational structure leads to improvements in efficiency through specialisation. As we will see, it also enables a firm to realise system economies. By restricting the client's ability to engage in organisational innovation, total outsourcing reduces its effective search. Increasing the extent of total outsourcing increases the possibility of lockin to an inefficient organisational architecture, negatively impacting long run productivity.

Section 4 describes the model that is used to investigate the complex relationship between organisational innovation, total outsourcing, and productivity growth. It specifies the alternative strategies for organisational innovation available to the firm, the way in which learning is modelled, the decision rules for IT adoption, and the outsourcing of activities. Section 5 discusses the results of simulations performed on the model. Section 6 concludes and points to new directions for further research.

\section{Potential benefits and problems of outsourcing}

There has been a rapid increase in the level outsourcing, across a wide range of areas and activities, in manufacturing and services over the last two decades. A notable growth area is the externalisation of information technology (IT) services. From 1989 to 2006, the global IT outsourcing market grew from an estimated US $\$ 3$ billion to just over US $\$ 250$ billion (Willcocks and Lacity 2006). A recent Forrester study of US firms (McCarthy 2002) indicates that computer services account for $26 \%$ of all outsourcing (Fig. 1). The IT outsourcing 


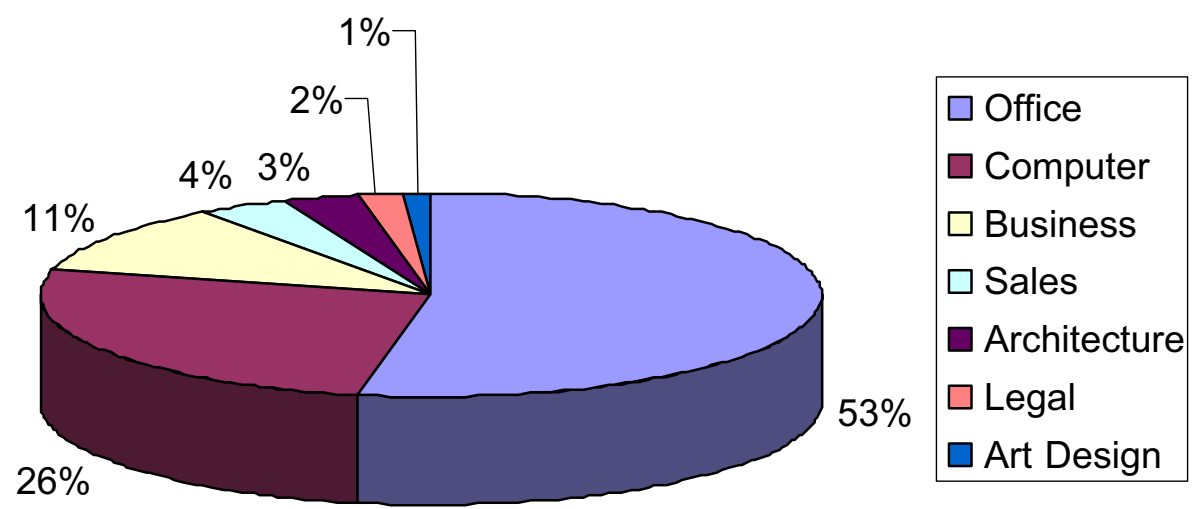

Fig. 1 Variety of activities being outsourced. Source: McCarthy 2002

revolution has been fuelled by significant developments in countries such as India and China (as new entrant IT providers) and by the adoption of packaged organisational software; e.g. office based systems, Enterprise Resource Planning (ERP) and Customer Relationship Management (CRM).

IT based activities represent a significant proportion of office services, accounting for $53 \%$ of all outsourcing by US firms. This includes basic back-office activities such as payrolls. The remaining share is made up of advanced, backoffice activities such as legal services, and client-facing front-office activities in sales and marketing. Sources such as Indobase and Gartner highlight the present and future growth of Business Process Outsourcing (BPO).

\subsection{Potential benefits}

Research on outsourcing can be found in four different literatures: transaction cost economics, strategic management, information systems, and services innovation. Three key potential benefits are highlighted in these literatures, and are consistently identified as key drivers in CEO surveys such as the Morgan Chambers study of the top 100 FTSE firms (Morgan Chambers 2001) and the Outsourcing Institute's study of outsourcing in Japan (Outsourcing Institute 2005). These are: the reduction of direct operating costs, specialisation in core competences, and the substitution of non-core competences with inputs from a specialist provider.

Transaction cost economics dates back to Coase (1937). It predominantly focuses on the reduction of direct operating costs, i.e. the wage bill and managerial administrative overheads. Williamson (1985) argues that, ultimately, the sourcing decision depends on the scope for cost reduction and the degree of asset specificity. A firm should outsource activities when this minimises the sum of production costs and transaction costs. This is likely to be when the level of asset specificity is low. 
Where transactions cost economists focus on the reduction of direct operating costs, other scholars highlight the benefits that can arise through specialisation and substitution. First, an outsourcing firm can focus and devote more resources to developing its core competences. Second, a substitution effect arises when an outsourcing firm replaces its non-core competences with inputs from a specialist provider with greater knowledge depth, which invests more in these competences, is more efficient, and is able to offer higher salaries to attract more highly skilled staff.

The nature and potential impact of client-provider interactions has received much attention from services innovation scholars. Of particular interest is the 'co-production thesis'. It is argued that knowledge intensive business service (KIBS) providers do more than provide higher quality inputs; they engage with their clients in the co-production of new knowledge and material artefacts (Gallouj and Weinstein 1997; Antonelli 1998; Sundbo 1998; Preißl 2000). For the client and the KIBS provider to interact in this way, there must be a semipermeable boundary between the organisations. Developments in the skills and competences of one will affect a change in the skills and competences of the other (Gallouj and Weinstein 1997).

\subsection{Total outsourcing relationship}

The co-production thesis raises a most important issue. Co-production is founded on the existence of an 'integrated outsourcing' relationship. This integrated outsourcing relationship lies at one end of a spectrum of clientprovider relationships. At the opposite end of the spectrum lies the 'total outsourcing' relationship. In practice, the vast majority of contracts take the form of total outsourcing relationships. This fact has been neglected by services innovation scholars. Indeed, the issue of control is generally ignored in the outsourcing literature. Yet it is of vital importance to any discussion about the long run impact of outsourcing on productivity.

Total outsourcing is by far the most common form of client-provider relationship. Total outsourcing involves the complete hiving-off of one or more activities by the outsourcing firm for a set period of time. Control of the outsourced activities, and their administration, are passed over to the service provider-total outsourcing involves the sourcing of between $80 \%$ and $100 \%$ of an activity from a client to a supplier (Willcocks and Lacity 2006). As a consequence of the strict division of labour between client and service provider, there is little or no interaction between provider-client knowledge and competence bases. There is certainly no co-production. The relationship is contractual. The provider undertakes to deliver a pre-specified set of inputs or services to the client at a set price and quality for a number of years.

As we shall see, the nature of the total outsourcing relationship is crucial to the short and long term impact of outsourcing on the client firm. Substituting expensive in-house labour with cheaper provider labour may well deliver a short term cut in the wage bill and in the administration of those (formerly in-house) activities. If loss of client control under total outsourcing restricts its 
capacity to engage in organisation innovation and restructuring — an important source of TFP improvement-then outsourcing may well have a negative impact on its long run productivity growth.

\subsection{Problems setting up and managing contracts}

Managers face a set of practical problems in trying to define core competences, and in the drawing up and monitoring contracts. Transaction cost economists highlight the problem of hold-up. This arises because the client and the provider need to make relationship-specific investments that are of little or no value outside that relationship. Given the problem of writing complete contracts prior to making these investments, there may be underinvestment in external sourcing. This has prompted a theoretical debate about the specification of contracts (Grossman and Hart 1986; Hart and Moore 1999), contractual protection (Klein et al. 1978), breach of contract (Edlin and Reichelstein 1996), and renegotiation (Hart and Moore 1988; Aghion et al. 1994).

The strategic management and IS literatures discuss the practical problems involved in identifying 'core' and 'non-core' competences. They also discuss how managers invariably underestimate the positive externalities that arise due to interactions between particular sets of business activities. In-depth individual case studies, such as McIvor (2003) and Willcocks and Plant (2003), reveal inconsistencies and a lack of clarity in the way managers interpret core competences, and challenge the usefulness of core competence theory as a basis of outsourcing. Activities that were believed to be non-core are later realised to be core, or, alternatively, to directly impact on core activities. ${ }^{1}$

Willcocks and Plant's study of 78 US, European and Australasian organisations identifies some (all too rare) examples of successful core competence management at Dell, Cisco, Direct Line and Tesco. Dell focused on research and development, information management, and the customer buying process while outsourcing input production to suppliers. Tesco's focus on core activities meant it decided to control its online shopping in-house but externalised online banking, which it perceived to be non-core. Direct Line adopted a similar approach regarding the development of Jamjar.com and Directline.com. Against these success stories, Willcocks and Plant discuss a number of well publicised outsourcing failures. These include the outsourcing of inventory management systems and internet development. Leading firms, such as Alamo, J.S.Sainsbury, Cable and Wireless, and J.P. Morgan Chase, mistakenly perceived these to be non-core activities and subsequently needed to re-insource.

The management and IS literatures also discuss unforeseen transaction costs involved in drawing up and managing contracts, and the problems and

\footnotetext{
${ }^{1}$ Managers are presumably not helped by fundamental disagreements about what actually constitutes a core competence. For example, Prahalad and Hamel's (1990) definition is based on enhanced customer value, competitor differentiation, and extendability. By contrast, transaction cost writers, such as Reve (1990), use asset specificity to define core competences.
} 
costs involved in reversing sourcing decisions. IT is an attractive candidate for outsourcing for many small and medium sized firms because it is one of the most expensive parts of the organisation to establish and maintain (Earl 1996). Unfortunately, the potential cost savings of IT outsourcing can be (and often are) eaten away by unforeseen costs that are extremely difficult to quantify at the outset, but which are essential to the make-buy decision. These include initial vendor search and contracting set-up costs, transition costs involved in transferring in-house IT activities to a vendor, and the costs of managing an ongoing contract. The latter is usually the largest cost. It includes the monitoring of IT vendors, ongoing bargaining and sanctioning (where necessary), and negotiating necessary contract changes (Barthelemy 2001). Further costs are incurred when a contract is unsuccessful. These involve finding a new vendor or, alternatively, re-insourcing IT.

Barthelemy's survey of 50 IT outsourcing firms found that $14 \%$ deemed the outsourcing operation to be a failure (Barthelemy 2001). Yet, despite this, he identified strong managerial inertia to re-insourcing. When managers initially decide to outsource an IT system, they generally do not consider the possibility of, or mentally prepare themselves for, re-insourcing at a later date. Barthelemy found that managers prefer to search for another vendor rather than consider re-insourcing. Additionally, IT is a lumpy investment with high sunk costs. It is difficult to rehire skilled IT staff, and costly to purchase new IT systems and train general staff. Maintaining external contracts is also expensive, however. Miozzo and Grimshaw (2005) observe that IT suppliers are not turn-key; they are not easily substituted because markets are thin. What is more, as outsourcing firms lose internal IT skills over time (as a consequence of staff turnover and/or the technology frontier continuing to move ahead), so monitoring contracts becomes more difficult and more expensive.

The same set of issues are raised in research on the outsourcing of nonIT services (see, for example, Hinks and Hanson 2001; Domberger 1998; Steinmueller 2003). With regards to R\&D, Prencipe (1997) highlights the danger of outsourcing complex production and advanced R\&D activities, based on simple notions of core and non-core competences. Outsourcing can seriously impair the development of new (core) technological competences in the future. For this reason, Brusoni et al. (2001) emphasise the importance of retaining control over $\mathrm{R} \& \mathrm{D}$, and the ability to coordinate the $\mathrm{R} \& \mathrm{D}$, design, and manufacturing activities of suppliers.

\subsection{Long term productivity}

Given the amount of attention that outsourcing has attracted, surprisingly little empirical research has been conducted on the long term effects of outsourcing. Further, those studies that do exist tend to focus on manufacturing rather than services. Given the importance of services in developed economies, and the fact that outsourcing within service sectors accounts for the majority of all outsourcing, this is unfortunate. 
A limited number of empirical studies have investigated the short term and long term effects of outsourcing on costs and productivity growth. Of particular note here are Görzig and Stephan's (2002) panel study of German manufacturing companies, Bengtsson and von Hartman's (2005) study of outsourcing by medium and large size Swedish firms, Lacity and Willcocks's (1998) detailed study of IT outsourcing by US and UK firms, and Gianelle and Tattara's (2007) panel study of outsourcing by textile, clothing and footwear manufacturers in the Veneto region of Italy. In addition, a number of individual case studies exist in the strategic management literature and in the information systems literature.

Görzig and Stephan (2002) is one of the earliest attempts to estimate the effects of outsourcing on plant productivity using micro-data. The study examines a panel dataset of 43,000 German manufacturing companies for the period 1992-2000. Görzig and Stephan estimate firm performance, measured by the returns per employee and the return on sales. ${ }^{2}$ The analysis considers material inputs, external contract work, and services outsourcing. Estimates include both a between-firm specification (where all observations are averaged for each firm), and a within-firm specification (where they control for unobserved heterogeneity and exclude all time-invariant variables). The former estimated model is interpreted as the long run model, and the latter as the short run model. In the long run, Görzig and Stephan find a negative and statistically significant correlation between outsourcing and productivity. In the short run they also find a negative, statistically significant correlation for services outsourcing and productivity.

Bengtsson and von Hartman (2005) examine a survey sample of 267 medium and large size firms in Sweden. ${ }^{3}$ They found that outsourcing companies enjoy cost reductions in the short run, principally through cutting the wage bill. However, they find that administrative overheads (i.e. management and administrative costs) increased. This is a consequence of the more complex logistics required to manage the interaction between the outsourced activities and in-house activities. Even with more complex logistics in place, outsourcing firms report a strongly negative impact on lead times, delivery times, and accuracy. Bengtsson and von Hartman report that these logistics problems were more common amongst companies that outsource to low-cost countries.

Turning to the literature in IT outsourcing, one would expect to find a discussion of the impact of different outsourcing relationships on the success/failure of outsourcing IT to specialist KIBS suppliers. Certainly a significant number of high profile, private and public sector organisations have chosen to outsource their IT activities over the last couple of decades. Promi-

\footnotetext{
${ }^{2}$ These are used as indicators of productivity. Each makes use of the gross operating surplus (GOS). The first is GOS divided by employment, the second is GOS divided by gross production. ${ }^{3}$ The analysis is based on a set of written questionnaires collected from 267 firms. All firms have $50<$ employees and are drawn from the ISIC sectors 28-35: metal goods, machinery, office equipment and computers, other electronics, telecoms, instrumentation, and the automotive industry.
} 
nent examples in the private sector include Eastman Kodak, Caterpillar, RollsRoyce, MacDonald Douglas, JS Sainsbury, Continental Bank, and Continental Tires. Yet, while these deals have received much media attention, only the general aims and criteria of the arrangements have been disclosed by official parties. Take, for example, the first major total outsourcing deal between Eastman Kodak and IBM. Officially, all that is stated is that this relationship started in 1989, when Eastman Kodak chose IBM to handle the vast majority of its data handling arrangements (Polilli 1989), and according to an IBM press release (18th October 2005), the relationship continues to evolve with IBM delivering a range of business support functions. Lack of information is also striking in relation to Nestle's US\$500 million deal with IBM, and the US $\$ 1$ billion deal between the British retailer Sainsbury's and the IT vendor Accenture (2000-2005). Writing in the Financial Times, Alan Cane suggests that this lack of information is due to the frighteningly large percentage of IT sourcing projects that end in failure: they are either late, over budget, do not work, or do not meet the client's needs (Cane 2007). Cane suggests that both the vendor and the client have too much at stake, in terms of reputation and customer confidence, to publicly air these failures. ${ }^{4}$

To our knowledge, Lacity and Willcocks (1998) is the only empirical study to have considered the effect of different sourcing arrangements on the success/failure of IT outsourcing. Their analysis is based on a detailed sample survey that was completed by 40 US and UK companies. They define total outsourcing as an arrangement where $80 \%$ or more of the IT activity is passed to an external supplier. Integrated sourcing refers to clients who use external suppliers but retain $20 \%$ to $80 \%$ of IT activities in-house..$^{5}$ Total insourcing is where as at least $80 \%$ of the IT activity is controlled by the client.

Lacity and Willcocks consider clients' perceptions of success, defined in terms of financial returns. With respect to reducing costs, total outsourcing arrangements were only successful in $29 \%$ of cases. By contrast, $67 \%$ success was reported for total IT insourcing, and $85 \%$ success for IT integrated outsourcing. The size of the IT activity or function being outsourced appears to have no impact on success or failure. Rather, the critical success factors identified by Lacity and Willcocks are (1) the length of contract, and (2) the type of contract that is drawn up. Firms that award contracts of 4 or less years achieve significantly greater cost savings than firms that award contracts of more than 4 years. By far the worst performance was achieved by firms awarding contracts for 7 years or longer. This finding is particularly important given that the overwhelming number of total outsourcing arrangements are long terms contracts of between 7 and 10 years. With regards to the type of contract that is drawn up, Lacity and Willcocks find that detailed 'fee-for-

\footnotetext{
${ }^{4}$ The notable exception that proves the rule is the legal action currently being taken by British Sky Broadcasting (BSkyB) against Electronic Data Systems (EDS). This is for damages in relation to a contract for a call centre and a Customer Relationship Management (CRM) system.

${ }^{5}$ Another label frequently used in the information systems literature is 'selective outsourcing'.
} 
service arrangements' have a $91 \%$ success rate; far higher than alternative arrangements.

Other writers in the information systems literature have been critical of companies who outsource large scale, long term IT projects with single suppliers. Weill and Broadbent (1998), highlight the loss of strategic flexibility and effectiveness in such arrangements. This negatively affects the client's ability to respond to changes in demand and to competitors' strategic moves. Loh and Venkatraman (1992) and Lacity and Hirschheim (1993) highlight the economic consequences of vendor self interest and complacency once the contract is agreed, requests for additional fees, and the consequences of clients becoming locked into outdated services or technologies, increasingly incapable of monitoring vendor performance. They also observe a consequential loss in responsiveness to changes in demand.

\subsection{Innovation}

Given the emphasis placed on the potential benefits of outsourcing for innovation, particularly within the KIBS literature. Surprisingly few empirical studies have actually been conducted to date. With regards to IT outsourcing, there is the 'CIO's Exclusive Outsourcing and Innovation Survey' (Overby 2007). Two main findings arise from this online survey of 290 senior technology executives. First, only $24 \%$ of executives believe that outsourcing contributes to IT innovation (versus $76 \%$ for insourcing). Second, significantly more executives are dissatisfied with the levels of innovation generated by long distance global outsourcing (off-shoring), compared with domestic outsourcing. This survey is interesting but highlights the problems with the research in this field-it lacks detailed analysis, rigor in terms of its research method, and focuses on IT sourcing in general (not total outsourcing specifically). Additional empirical research is required for a deeper understanding of the relationship between diverse forms of outsourcing and innovation.

Turning to non-IT outsourcing, there is Gianelle and Tattara's (2007) study of total outsourcing by textile, clothing and footwear manufacturers in the Veneto region of Italy. Their findings are very much in line with studies on the total outsourcing of IT services. Gianelle and Tattara have a panel sample that contains 48 joint stock companies, based in the Veneto area. These are mainly medium-size firms which have delocalised important phases of production. Gianelle and Tattara's statistical analysis identifies a one-off short run cost reduction as Italian labour is substituted by cheaper foreign labour. However, they find that outsourcing firms achieve zero long run productivity gains. Gianelle and Tattara explain that this is due to the fact that service providers' machinery and production techniques do not improve over time. In other words, Smithian specialisation of the production process has not led to innovation or productivity improvements in the contractor firms. Indeed, Gianelle and Tattara report that there are documented cases of the machines 
previously used in the Veneto area being shipped abroad to be used by foreign contractors. Gianelle and Tattara observe that the reorganisation of production may bring about organisational innovations in foreign contactors in the future, but that these have not happened to date. Only when this occurs will there be long term improvements in productivity.

To briefly summarise, existing empirical evidence indicates there are two key disadvantages to long term, total outsourcing contracts. First, total outsourcing relationships reduce the capacity of client firms to engage in organisational innovation, i.e. to organise and develop new organisational structures that better capture the positive externalities that exist between interrelated activities. This is because control over the specification and development of outsourced activities is passed over to the contractor. Second, in drawing up long term contracts, clients effectively give monopoly power to the contractor. The evidence indicates that specialisation advantages and productivity improvements that accrue to the contractor are not passed on to the client but are kept by the contractor in the form of higher profits. Taken together, the empirical evidence indicates that total outsourcing relationships, fixed over long term contracts, has a detrimental impact on clients' productivity growth.

\section{Optimal search, organisational innovation, and outsourcing}

Having discussed the existing empirical data, let us next consider the link between total outsourcing, organisational innovation, and productivity growth. While the empirical data indicates a negative long run correlation between total outsourcing and productivity growth, and between total outsourcing and organisational innovation, the data does not provide information on the complex links between total outsourcing, organisational innovation, and productivity growth. ${ }^{6}$ In this section of the paper we build on the so-called 'modular theory of the firm', which brings together Adam Smith's principles of specialisation and the division of labour with Herbert Simon's work on decomposition and complexity. This theory is important because it provides a platform for the model of organisational innovation and sourcing that is presented in Section 4.

Organisational innovation is a key source of firm total factor productivity growth (Harberger 1998). Indeed, the idea that organisational innovation drives economic growth dates back to Adam Smith's Wealth of Nations (Smith 1776). Chandler (1980) suggests that organisational innovation, leading to the more efficient use of existing resource inputs, accounts for up to one-third of all firm productivity growth in the US since the 1860s. This can take the

\footnotetext{
${ }^{6}$ See Brock's (1999) discussion of 'unconditional objects'. Empirical regularities provide us with information on the properties of stationary distributions. They do not provide information on the dynamics of the stochastic processes that actually generated them.
} 
form of new management structures, the development of new internal routines and work practices, new supply chain relationships, strategic alliances, and outsourcing.

The goal of organisational change is the identification of new organisational architectures that more effectively solve two key problems faced by managers: the 'fundamental coordination problem', and the 'agency problem'. The 'fundamental coordination problem' concerns the effective organisation of valueadding activities and information flows within the firm. New organisational architectures improve productivity by more effectively bringing together the externalities that exist between value-adding activities. These externalities exist between a set of related $\mathrm{R} \& \mathrm{D}$, design, production, and marketing activities within a firm (Langlois 2002), and between the activities of different firms along the supply chain (Jacobides and Winter 2005). Hence, the productivity of a particular organisational architecture depends on how effectively it enables a firm to manage (a) the externalities that exist between a set of in-house activities, and (b) the externalities that exist between its in-house activities and the activities of its suppliers/clients. The 'agency problem' concerns the ability of management to realise and enforce coordination and control in production, both internally and across the boundary of the firm. ${ }^{7}$ As discussed in our review of the empirical literature, there are costs involved in organising and managing internally held activities, and in establishing and managing interfaces between internally held activities and the activities of suppliers/clients. Altering the sourcing of activities changes these internal and external managerial overhead costs.

The link between organisational innovation and product/process innovation has been discussed by Chandler (1962, 1977), von Tunzelmann (1993), and Barras (1986). Organisational change is stimulated by new process technologies that require new internal routines and new work practices. The adoption of new IT systems is a particular case in point. IT adoption and development invariably requires organisational restructuring and process innovation in back office activities. It may also stimulate the development of new/improved services that require changes in client-facing front office competences and routines (Barras 1986).

Depending on their impact on internal and external coordination costs, different types and vintages of IT will stimulate verticalisation or deverticalisation. A particularly notable feature of internet-based IT, such as websites, internet-based EDI, and extranets, is the radical expansion of technical opportunities for the outsourcing of production, and a significant lowering of external coordination costs. The impact on internal administration costs, through applications such as intranets, is far more restricted. This asymmetrical impact on the costs of internal and external coordination (the agency problem), and on the feasible opportunities for production and the division of labour (the fundamental coordination problem), has altered the relative

\footnotetext{
${ }^{7}$ Issues of agency and control in the firm are addressed in detail by Reinstaller (2007).
} 
efficacy of outsourcing vis-à-vis performing activities in-house. The consequence is a flattening of organisational hierarchies in large firms, associated with vertical disintegration, and individual business units are becoming smaller in size.

The current situation contrasts sharply with the impact of previous vintages of IT, such as those discussed by Chandler. Calculators, typewriters, Hollerith electric tabulating machines, and book-keeping machines were only applicable to internal administrative activities (Yates 2000; Reinstaller and Hölzl 2004). Consequently, these ITs significantly reduced internal coordination costs while having little or no impact on external coordination costs. These earlier IT technologies were essential to the development of the modern hierarchical organisation, which occurred between the 1860s and the 1930s. Indeed, large corporations were the key purchasers of IT technologies (as they are today). Further improvements in these ITs enhanced the ability of large u-form and $\mathrm{m}$-form businesses to grow in size. The result was a tendency towards vertical integration as more and more activities were brought in-house.

These stylised facts provide us with a transmission mechanism between the adoption of new IT, organisational innovation, and outsourcing. The transmission mechanism is important because it enables one to consider the coordination costs and agency costs of alternative types of IT and the effect these have on organisational innovation and sourcing.

The modular theory of the firm enables one to explore the relationship between organisational innovation, outsourcing, and productivity growth. This theory is founded on the twin principles of increasing specialisation and the modularisation of complex organisational structures. This brings together Adam Smith's principles of specialisation and the division of labour (Smith 1776) with Herbert Simon's discussion of the decomposability of complex problems (Simon 1996, 2002). Key contributions to the theory have been made by Langlois and Robertson (1995), Baldwin and Clark (1997), Langlois (2002, 2003a), Marengo and Dosi (2005), and Baldwin (2007).

Simon $(1996,2002)$ addressed the generic issue of problem-solving activity within complex systems and suggested that modularisation is the means by which problems are made more manageable. Modularisation involves the grouping of interconnected elements within a system, to create distinct subcomponents (module). In addition to reducing the complexity of a problem, by breaking it down into a smaller number of sub-components, modularisation means improvements can be made to just one sub-component of the system, avoiding the need to simultaneously change all the other parts of the system (which would be the case if there were no modularisation). There is a cost, however. This arises through the need to establish and maintain interfaces that ensure each sub-component is compatible with all other sub-components. Interfaces ensure that the whole structure functions in an integrated way, while maintaining a high degree of independence for each sub-component.

Translating this approach to the current discussion, organisational innovation is a search process involving the development of new organisational architectures that create/destroy (1) modular components containing interrelated 
value-adding activities, (2) the administrative interfaces between modular components, and (3) the internal/external sourcing of these modules individual activities, and even whole modules of interrelated activities.

In discussing the link between the modularity of an organisational structure and TFP improvements, a theoretical link is made to Adam Smith's principle of specialisation through the division of labour. Smith's classic example of the pin factory in the 'Wealth of Nations' is, in fact, a discussion of one way in which complexity can be tackled-by breaking down and dividing a range of complex value-adding processes into a finer set of specialised functions. Through specialisation, the efficiency of production is raised. Cooperation is a necessary prerequisite for specialisation. Each activity must be carefully orchestrated. Workers become complements to one another, rather than substitutes (Leijonhufvud 1986). This coordination function must be hardwired (to a greater or lesser degree) into the spatial and temporal interfaces between specialised operations and specialised operatives (Langlois 2003b). Smith made it clear that the specialisation principle is generic and holds in all aspects of business organisation (Langlois 2003b). This includes decisions about what to produce, the inputs that are required, what should be produced in-house or bought in markets, the geographical location of production, sales etc., the appropriate organisation structure of the firm, and the information and communication requirements of the organisation.

Placing Smith's principle of specialisation within Simon's framework of decomposable complex systems, we see that the problem facing managers is how to decompose a set of interrelated, value-adding activities into a set of modular subsystems and, second, how to coordinate these subsystems. An optimal organisational structure is one in which positive externalities between activities are maximised while negative externalities are minimised. This is what drives the process of modularisation, determining the elements to be placed within modules, and the interfaces between modules. Through this modularisation process, the interactions between a set of activities are identified and transformed into a nearly decomposable system. ${ }^{8}$

Let us now consider the relationship between organisational innovation and total factor productivity (TFP). There exist two potential sources for TFP improvement. The first is 'system economies', of the type discussed by Nightingale et al. (2003). Through the development of new interfaces that improve control of interactions between a given set of modules, managers improve TFP. In practice, this entails the development of more effective managerial service activities to integrate and control a the set of productive activities currently performed by the firm. Through improved managerial control, the firm approaches a given productivity frontier, improving TFP. The second source of TFP improvement is organisational innovation. Increasing

\footnotetext{
${ }^{8} \mathrm{~A}$ fully decomposable system is one in which all externalities can be located within modular subsystems. In a nearly decomposable system, externalities exist between subsystems as well as within sub-systems.
} 
the modularity of the organisational structure pushes the productivity frontier forwards. Organisational innovation may either involve the splitting of administrative tasks into a greater number of organisational modules or, alternatively, the integrating of organisational modules to increase control over the modular productive elements and their interaction. A superior organisational architecture improves the coordination and control of materials, funds, services, and information that flows through the complex supply, production and distribution activities of the firm, raising TFP.

Organisational innovation is an ongoing process: innovation begets further innovation over time. Through experimentation, managers gain a better understanding of the externalities that exist between activities, and see new opportunities that can be afforded by breaking down 'departmental silos' and creating novel synergies between activities. For instance, creating stronger interactions between the sales and production departments may lead to new product opportunities. These, in turn, may provide economies of scope and, if the firm is able to develop new markets, economies of scale. As Baldwin and Clark (1997) observe, the more modular an organisation's architecture, the greater the likelihood of stimulating further modular innovation. The process of organisational innovation also explores new sourcing possibilities. To quote Baldwin, "Modularizations create new thin crossing points where transaction costs are low. These new module boundaries provide points of entry for competitors and breakpoints where vertically integrated firms and industries may split apart... Strategies, knowledge and technologies all change over time, and the location of transactions changes as well." (Baldwin 2007, p.4, italics added).

To summarise, organisational innovation is a search process by which the firm develops new organisational structures that capture, within a nearly decomposable system, the externalities that exist between activities. This is achieved by creating modules in which the positive externalities of closely related activities are maximised, and by developing interfaces that maximise the externalities between modules. Additionally, organisational innovation is an ongoing process of experimentation with the internal and external sourcing of modules. The sourcing decision and the opportunities for the division of labour are, in part, technologically determined. Of particular note is the effect of new IT on agency costs and on internal/external coordination costs. These affect the direction of organisational innovation, outsourcing decisions, and long run productivity. We develop a simulation model in order to examine the complex interactions between new IT, organisational innovation, outsourcing, and TFP. The core features of this model are discussed in the next section of the paper.

\section{A model of organisational innovation, IT, and total outsourcing}

Empirically grounded modelling uses stylised empirical facts about the micro features of the system to inform the modelling process. Further, one or more 
industry/macro level observations or stylised facts are used as a benchmark to test the validity of the simulated outputs that are generated by the model. ${ }^{9}$

Our model of organisational innovation is informed by five stylised facts discussed in Section 3:

1. organisational innovation is concerned with identifying and capturing the externalities between a set of value-adding activities within organisational modules,

2. maximising externalities also requires improved managerial control of the interfaces between modules,

3. there is an essential connection between the scope of organisational innovation and potential productivity growth,

4. total outsourcing transfers the control of modules to a service provider, and

5. new IT alters the technological opportunities for internal/external sourcing, and the relative cost of sourcing activities internally/externally.

The model also uses empirical evidence on the strategic process of innovation and outsourcing furnished by Tayles and Drury (2001). This was gleaned through an action research project with a major UK engineering company. The decision structure identified by Tayles and Drury is replicated in the model, in a slightly simplified form (Fig. 2).

First, an activity is randomly selected (box 1). This may, for example, be a bottleneck that has been identified. Management then consider alternative innovation strategies to improve TFP (box 2). The options are (a) organisational restructuring, taking the form of modular change, or (b) the incremental improvement of existing modules. The former is an exploration strategy: the firm actively explores the dimensions of the search landscape (i.e. to identify the globally optimum design) by altering the modular structure of the organisation. The latter is an exploitation strategy: it seeks to incrementally improve performance by exploiting the current set of resources contained within the existing modular configuration.

Managers are boundedly rational, in that they do not know the characteristics of the stochastic process that generates incremental and radical innovations, or the final payoffs to each strategy. For each strategy, management must estimate the likely outcome of an exploration or an exploitation strategy ${ }^{10}$ based on the degree of organisational decomposition that is required (box 3 ), on production costs (box 6), on managerial overheads and coordination costs (box 7), and on profits, given expectations of price changes and demand elasticity (box 8).

Following Tayles and Drury, the sourcing decision is the next step in the decision process (boxes 11 to 18). Two parameters are significant here. The

\footnotetext{
${ }^{9}$ For an in-depth discussion of empirically grounded modelling, the interested reader is referred to the special issue of Computational Economics edited by Birchenhall et al. (2007).

${ }^{10}$ March (1991) discusses the long term need for firms to simultaneously hold exploration and exploitation strategies.
} 


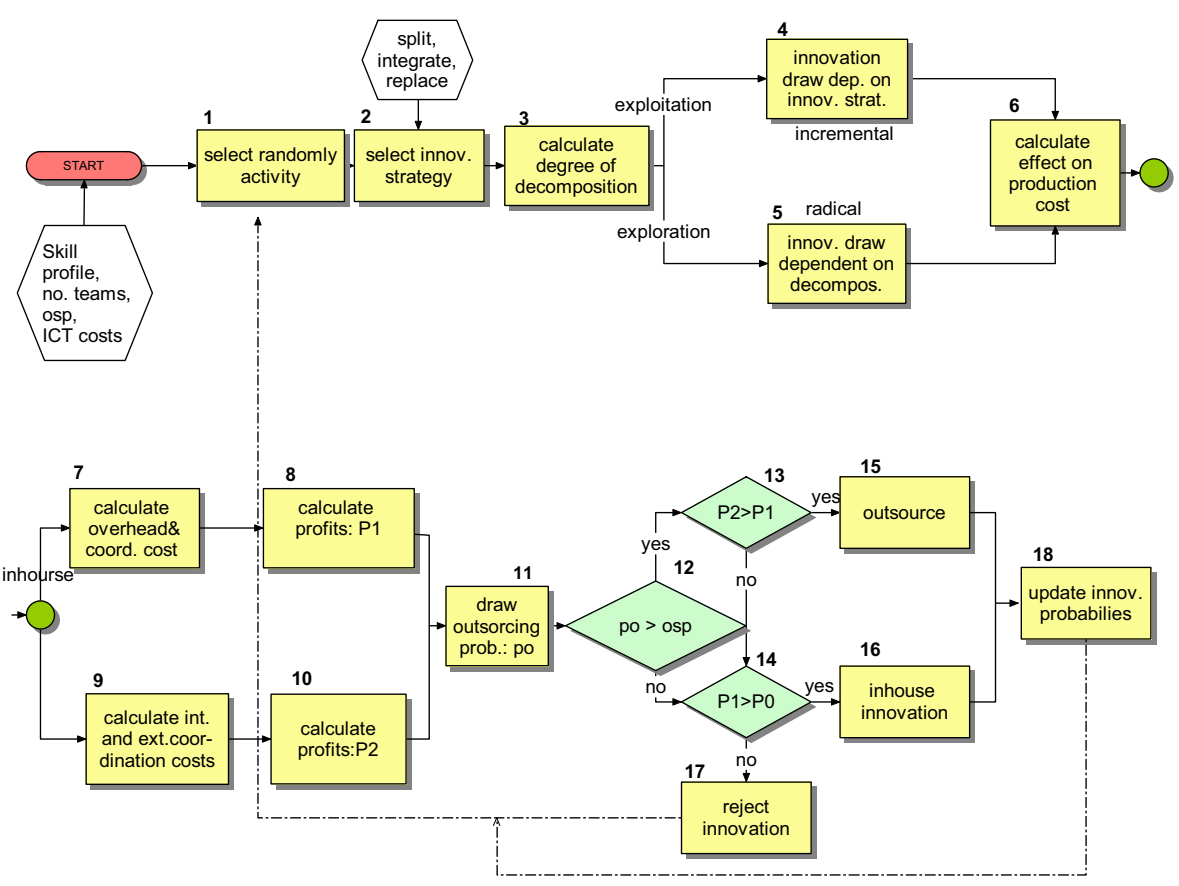

Fig. 2 Flowchart of the decision making structure. Based on Tayles and Drury (2001)

first is the management's propensity to outsource ('OSP' in box 12). This risk attitude to outsourcing is an exogenously determined variable. It represents a persistent managerial trait. This is likely to depend on a number of factors, such as the risk attitude of the individual managers that make up the management board and the power of these individual managers to influence decisions. The outsourcing propensity (OSP) may also be subject to external influences, such as media and consultancy reports extolling the potential virtues of outsourcing, and to the influence of sourcing decisions made by competitors or by firms in other industries. By altering the value of this parameter, one can analyse the effect of different propensities to outsource on organisational innovation and, hence, long run TFP.

For a given outsourcing propensity (OSP), a draw is made on a uniformly distributed random variable. This indicates whether the option to outsource a module is available (box 11). In the model we assume that KIBS providers have cost advantages in the delivery of some (though not all) business activities. Hence, the 'optimal organisational design' for the contractor is not a corner solution but some combination of insourced and outsourced activities.

The process of 'total outsourcing' involves a KIBS-client contract that specifies the delivery of a specific service of a fixed quality and a fixed price. Following the empirical evidence discussed in Section 2, once the outsourcing firm enters a total outsourcing contract, it shuts down its own productive activity in this area. 
A second exogenous factor is the type of IT that is available. This is modelled as an exogenous parameter that determines the relative impact of IT on external and internal coordination costs. By altering the values of this parameter we are able to analyse the impact of IT on organisational innovation, insourcing/outsourcing and TFP for two scenarios. The first scenario is that of early IT technologies, such as those discussed by Chandler, that reduce internal coordination costs more than external coordination costs. The second scenario is that of internet-based ITs, which reduce external coordination costs far more than they reduce internal coordination costs.

The decision to adopt a new organisational architecture means the firm implements a particular organisational strategy and-in the case of a modular innovation-a particular sourcing decision (boxes 15, 16, 17). Using this new organisational architecture, the firm engages in production and sells the produce on the market.

The boundedly rational firm adaptively learns from its experience. Using information on the resulting payoffs, the management updates its expectations about the effectiveness of the innovation strategies that it employs (box 18). The probability of choosing a particular strategy in the next period endogenously changes as a consequence of this reinforcement learning. As described by Arthur (1991), each strategy has a weighted probability that it will be chosen by the management. This weighted probability increases or decreases over time according to how more or less successful it proves to be in improving performance.

The extent of organisational specialisation ultimately depends on a number of demand and supply side factors. On the demand side, it depends on the extent of the market (i.e. increasing levels of population and/or income), and the degree of competition (the elasticity of demand) (Young 1928). On the supply side, it is affected by the availability of IT, which enables activities to be subdivided and coordinated in new and better ways (the agency problem). Together, these demand and supply side factors determine the extent to which activities can be effectively modularised and technical hierarchies established.

Let us consider some specific aspects of the model in greater detail.

\subsection{Organisational architectures}

The modular architecture of an organisation can be modelled using the NK approach of Kauffman and Altenberg. ${ }^{11}$ We assume the administration of a firm delivers $\theta$ services to productive routines that generate a firm's valueadded. The quality of these services has an impact on the performance of productive routines. These services are produced by organisational routines $m_{1}$ and $m_{2}$, which produce a subset of all services. These two routines are linked together through a coordination routine $m_{1}^{a}$. More generally, the organisation

\footnotetext{
${ }^{11}$ See Altenberg (1995), Wagner and Altenberg (1996), Kauffman et al. (2000), and Schilling (2000).
} 
of a firm consists of a set of $n_{t}$ organisational modules or routines $m_{i}$, grouped by means of $n_{t-1}$ organisational routines $m_{j}^{a}$ into an organisational architecture $d_{t}=\left\langle m_{1}, m_{2}, \ldots, m_{n_{t}} ; m_{1}^{a}, m_{2}^{a}, \ldots, m_{n_{t-1}}^{a}\right\rangle \cdot{ }^{12}$ Since the division of labour inside the firm can vary over time, $n_{t}$ carries the time index $t$. The array $d_{t} \in D$ corresponds to a particular organisational architecture of the administrative activities that are in use within the firm at time $t$. It is drawn from a finite space $D$ of possible organisational architectures, which the management explores over time.

Each of the routines used in an architecture consists of $\lambda_{i}$ sub-routines or $m_{i}=\left\langle x_{h}\right\rangle_{h=1}^{\lambda_{i}} ; \lambda_{i}$ is allowed to vary across routines. These routines produce a vector $\theta$ of $k$ services for the productive routines that are operated by the firm. Together these output characteristics meet well defined customer needs in the market in which the firm operates. In our model, the organisation of a firm is therefore defined through the characteristics of an organisational architecture $d_{t}$ given by $n_{t}$ organisational modules $m_{i}$, and $k$ service characteristics. The number of modules $n_{t}$ is therefore a measure of the degree of modularity of the organisational architecture.

Strong externalities exist between the sub-routines $x_{h}$ in each module $m_{i}$, i.e. the performance of each sub-routine $\phi\left(x_{h}\right)_{t}$ at time step $t$ affects the performance of all other sub-routines in the module, and its performance is in turn influenced by all other sub-routines $\phi\left(x_{-h}\right)_{t}$ in the module. Consequently, the performance of all sub-routines $\phi\left(x_{-h}\right)_{t}$ change if $\phi\left(x_{h}\right)_{t}$ changes. It also follows that a sub-set $k^{i} \subset k$ of output characteristics is directly and indirectly affected by all $x_{h}$ sub-routines in a module $m_{i}$. The overall performance $\phi\left(m_{i}\right)_{t}$ of a module $m_{i}$ is therefore the result of negative and positive feedbacks between the sub-routines it contains. These interdependencies reflect a situation that is typical in team production, for example. The skills and activities of the team members are closely complementary and integrated and so, if one member performs under par, the efficiency of all other members is affected.

Externalities between sub-routines mean changing a particular service $\theta_{i}$ in module $m_{i}$ will alter the performance of connected sub-routines and services. In the simulations we will determine $\phi\left(m_{i}\right)_{t}$ by drawing $\lambda_{i}$ values from a uniform distribution with $\phi\left(x_{h}\right)_{t} \rightarrow$ Uniform[0,1] and calculating the average over the $\lambda_{i}$ sub-routines. The impact of all $n$ service producing administrative routines on firm performance is then given by, $\Phi_{t}=\frac{1}{n} \sum_{i=1}^{n} \phi\left(m_{i}\right)_{t}{ }^{13}$

Smithian specialisation involves splitting an existing module into two; each of the new modules focussing on producing a distinct service. Coordinating these new modules requires the introduction of an interface-an adminis-

\footnotetext{
${ }^{12} \mathrm{~A}$ routine is the process whereby a vector of inputs is transformed into a vector of outputs through the use of specific knowledge, skills and modes of coordination. See Nelson and Winter (1982, chapter 5). The terms module and routine are used interchangeably in this paper. We assume that routines are somewhat self-contained elements of the production process.

${ }^{13}$ This representation of organisational designs and their impact on the performance of productive activities corresponds to a generalised NK model (Altenberg 1995).
} 
trative service that coordinates the interaction between modules. Thus, $m_{i}$ modules are linked by $m_{j}^{a}$ managerial services. As the degree of hierarchy increases, so coordination overheads increase. This captures Simon's (1996) idea of increasing modularity as a means of solving complex problems. For a given set of internally-held activities (sub-routines), firms develop modules that contain inter-related activities, and separate out (into different modules) distinct sets of activities. By maximising positive externalities between interrelated activities, and minimising negative externalities between distinct activities, a firm can raise the TFP of a given set of productive inputs. This is our understanding of the 'system economies' described by Nightingale et al. (2003).

\subsection{Organisational learning: exploitation vs. exploration}

Managers use a set of $S$ strategies to explore the space of organisational architectures $D$. The strategy space $S=\left(s_{1}, s_{2}, s_{3}\right)$ consists of three strategies, each of which is used with probability $\mu_{j}$ at each time step $t$. Innovation strategy $s_{1}$ corresponds to incremental exploitation, driven by learning by doing. Here all values for $\phi\left(x_{h}\right)_{t+1}$ are redrawn. Performance improves if the average over the $\lambda_{i}$ sub-routines increases.

Strategies $s_{2}$ and $s_{3}$ are exploration strategies. These involve changing the organisational architecture of the firm. A firm identifies and neutralises one or more complementarities that bind sub-routines into a module. It then has one of two options. First, it can split a more complex activity into a number of less complex routines, and redesign its organisation accordingly. This decomposition strategy $s_{2}$, is the Smithian specialisation strategy discussed above. Henceforth we will refer to this as 'splitting'. The alternative option is to reorganise smaller production and organisation routines into larger, more complex modules. In this way the firm can explore the existence of externalities between previously unrelated routines. We will refer to this integration strategy, $s_{3}$, as 'job-enrichment'.

Both $s_{2}$ and $s_{3}$ lead to a change in the organisational architecture as poorly performing routines are replaced by better performing ones. ${ }^{14}$ In this case, all performance values $\phi\left(x_{h}\right)_{t+1}$ for the elements in the new module(s) are redrawn. If their joint average increases, this corresponds to a performance improvement. These strategies affect the performance $\Phi_{t}$ of productive routines through system economies. By improving control of productive routines, they push the productivity of a given technology towards its limit.

According to the modular theory of the firm, an increase in system modularity also leads to an improvement in the innovation rate. Modularity allows a better understanding of the workings of a system, making it easier to recombine routines, increasing the probability of discovering better ways of doing things. We will assume that, depending on the degree of decomposition of the

\footnotetext{
${ }^{14}$ Wagner and Altenberg (1996) have discussed decomposition and integration as potential evolutionary mechanisms of change within genetics.
} 
administration of the firm given by the number of routines $n$, the likelihood of discovering better ways of organising the production process increases if the firm invests in this exploration process. This will push ahead the performance $\Phi_{t}$ of productive routines by a factor $\left(1+\varepsilon_{t}\right)$, where $\varepsilon_{t+1}=\varepsilon_{t}(1+\tau)$. In the simulation, parameter $\tau$ has a small positive value as does $\varepsilon_{t}$ at $t=0$. The probability of the firm making an innovation $\varepsilon_{t}$ is determined by a Poisson process with an arrival rate $\alpha$. Following Silverberg and Verspagen (1994), we assume the firm's investments have first increasing and then decreasing returns. This is captured by a logistic representation of the arrival rate given by

$$
\alpha_{t+1}=\frac{\alpha_{\min } \alpha_{\max }}{\alpha_{\min }+\left(\alpha_{\max }-\alpha_{\min }\right)^{-\left(r * n_{t}\right)}}
$$

$\alpha_{\text {min }}$ represents a small autonomous probability of making a fortuitous innovation without investing in this type of innovation, $\alpha_{\max }$ corresponds to an asymptotic saturation level of the arrival rate. As can be seen, this process depends on the propensity to invest $r$ and on the degree of decomposition. This captures the innovation potential.

The firm maximises profits $\Pi_{d_{t}}\left(s_{t}\right)$. Its strategic behaviour is given by the probability distribution over the three alternative innovation strategies. This 'policy mix' $s_{t}=\left[\begin{array}{lll}\mu_{1, t} s_{1} & \mu_{2, t} s_{2} & \mu_{3, t} s_{3}\end{array}\right]^{\prime}$, with $\mu_{1, t}+\mu_{2, t}+\mu_{3, t}=1$, evolves through reinforcement learning, given some initial probabilities $\mu_{j, t=0}$. This probability should not be interpreted as conscious randomisation. Rather, it indicates (from the perspective of the outside observer) how likely it is that the decision maker will choose each of the three strategies. The reinforcement learning dynamics are those of Arthur (1991); each strategy is allocated a probability based to its past contribution to the performance of the firm.

$$
\mu_{j, t+1}=\mu_{j, t}+\frac{\Delta \Pi\left(s_{j}\right)_{t}-\mu_{j, t} \sum_{j} \Delta \Pi\left(s_{j}\right)_{t}}{\sum_{j} \sum_{t} \Delta\left(s_{j}\right)_{t}},
$$

where $\Delta \Pi\left(s_{j}\right)_{t}=\Pi\left(s_{j}\right)_{t}-\Pi\left(s_{j}\right)_{t-1}$ indicates the change in the performance improvement between two time steps $t$ and $t-1$, when strategy $s_{j}$ was used. From Eq. 2 we see the reinforcement mechanism. Strategies that have raised profitability in the past have a higher probability of being chosen again. Strategies that have not been as successful in raising profitability have a lower probability of being selected in each time step. Note that this method of probability updating shares certain features with a Polya Urn. There is path dependency in strategic choice, opening the way for chance events in the early selections to build up and have long term consequences. We will return to this issue in Section 5.

\subsection{Costs of production for a given organisational architecture and information technologies}

To simplify, we assume that white-collar routines are not productive in themselves but improve the utilisation and development of the firm's productive 
resources. More precisely, we assume that the services produced by an administrative activity $m_{i}$ have an impact on the performance of productive routines, $\phi\left(m_{i}\right)_{t}$. As previously mentioned, the impact on the unit costs of productive routines by all $n$ modules is given by $\Phi_{t}$. In order to run simulations, we choose a simple and well-behaved functional form to represent the effect of performance improvements on the unit costs of productive routines-one that captures the central ideas while ensuring unstable outcomes are avoided. We specify this as

$$
v c_{d_{t}}=w_{p} l_{p} e^{-\left(1+\varepsilon_{t}\right) \Phi_{t}}
$$

where $w_{p}$ is the average wage bill per unit of output paid for productive routines, and $l_{p}$ is the unit labour requirement.

Two types of routine govern the administration of the firm. The first type of routine produces managerial services for productive activities contained within a module. The second type of routine coordinates the interaction between these managerial services and modules. Outsourcing involves the outsourcing of the first type of routine as well as the productive activities within a module. We assume the number of services a module produces is proportional to its skill intensity, i.e. the more services an activity produces, the higher are the skills required to carry them out. This implies that the average wage paid to these routines is higher than to routines where only a few services are produced. For simplicity we assume that the unit wage cost of producing one service to productive routines is the same as carrying out one coordination task.

As discussed earlier in the paper, information technologies affect coordination costs. What is more, different vintages of IT have different relative impacts on internal and external coordination costs. Total administrative overhead costs are then defined by

$$
o c_{d_{t}}=\left(z l_{a} w \bar{\lambda}+(1-z) \sum_{\ell} p_{\ell}\right)+l_{c} w\left(v_{\mathrm{int}} e^{-\theta_{\text {int }}}+v_{\mathrm{ext}} e^{-\theta_{\mathrm{ext}}}\right)
$$

where $l_{a}$ and $l_{c}$ are the unit labour requirements for service and coordination routines, $w$ is the going wage rate paid per 'skill unit', $\bar{\lambda}$ is the average number of services produced in each administrative activity, $p_{\ell}$ are the prices paid for outsourced routines, $v_{i n t}$ and $v_{\text {ext }}$ are the number of internal and external coordination routines, and $\theta_{\text {int }}$ and $\theta_{\text {ext }}$ reflect the impact of IT use on internal and external coordination costs respectively. Variable $z(0 \leq z \leq 1)$ weights the unit costs of administrative services produced in-house and those externally produced by their respective share in the total number of services that are produced.

Suppose the firm has a propensity $r$ to invest part of its revenues to organisational exploration, i.e. through the modularity of its administration. These costs are then given by

$$
r c_{t}=r p_{t} q_{t}
$$

where $p_{t}$ and $q_{t}$ are the prices charged and the quantities sold at a time step $t$. 
If a specific module $m_{i}$ is outsourced, the contractor's unit cost of production is

$$
c s_{\ell}=l_{a, \ell} w \lambda_{i, \ell} \gamma_{\ell}+l_{c, \ell} w\left(v_{\mathrm{int}, \ell} e^{-\theta_{\text {int }}}+v_{\mathrm{ext}, \ell} e^{-\theta_{\mathrm{ext}}}\right)
$$

where $\gamma$ reflects the comparative cost advantage service firm $\ell$ has in producing the services of administrative activity $m_{i}$. In the simulations we assume that $\gamma$ $\rightarrow N\left(1, \sigma^{2}\right)$, i.e. the cost advantage is normally distributed around a mean of 1 with some variance $\sigma^{2}$. Variables $l_{a, \ell}$ and $l_{c, \ell}$ reflect the relative unit labour requirements for service producing and coordination routines, and $v_{i n t, \ell}$ and $\nu_{\mathrm{ext}, \ell}$ give the number of internal and external coordination routines the service supplier has to manage. Assuming the supplier has some market power, such that it is able to charge a positive mark-up $\xi$ over costs, the unit price for the services of supplier $\ell$ to the outsourcing firm is given by

$$
p_{\ell}=(1+\xi) c s_{\ell}
$$

In line with the empirical evidence, we assume that, once a module is outsourced, suppliers charge a fixed price for their services. Contract suppliers may enjoy Smithian specialisation advantages and/or scale economies as they grow, but these cost benefits are not passed on, in the form of lower prices, to the client firm. As discussed in Section 2, the empirical evidence suggests that markets are thin and that the suppliers of business services are typically larger and have more market power than their customers. Consequently, the market for outsourced business services is imperfectly competitive.

\subsection{Profits}

The firm faces a downward sloping (inverse) demand given by

$$
p_{t}=\frac{\mathrm{Is}}{q_{t}^{1 / \eta}}
$$

where $p_{t}$ is the price the firm charges at time $t$, Is is the amount of income customers spend on the firm's product, $q_{t}$ is the firm's output and $\eta(\eta>1)$, is the price elasticity of demand. Following standard theory, the optimum output and price for a given organisational architecture $d_{t}$ are given by

$$
q_{d_{t}}^{*}=\left[\frac{\mathrm{Is}(1-1 / \eta)}{v c_{d_{t}}+o c_{d_{t}}}\right]^{\eta}
$$

Therefore, for each organisational architecture $d_{t}$, the firm seeks to maximise profits

$$
\Pi_{d_{t}}^{*}\left(s_{t}\right)=\operatorname{Is}\left[\frac{\operatorname{Is}(1-1 / \eta)}{v c_{d_{t}}+o c_{d_{t}}}\right]^{\eta-1}-\left(v c_{d_{t}}+o c_{d_{t}}\right)\left[\frac{\operatorname{Is}(1-1 / \eta)}{v c_{d_{t}}+o c_{d_{t}}}\right]^{\eta}-r c_{t}-c_{t}
$$


by reducing unit costs of production. In our model this is achieved by pursuing different strategies $s_{t}$ of organisational innovation. The term $c_{t}$ reflects fixed capital costs. Given a constant capital-output ratio, the firm must invest or disinvest as output changes.

\subsection{The innovation and outsourcing decisions}

Decisions to conduct organisational innovation and outsource depend on economic profitability. The management of the firm calculates the expected profits $E\left[\Pi_{d_{t+1}^{\prime}}\left(s_{t}\right)\right]$ that the new organisational architecture $d_{t+1}^{\prime}$ is likely to generate, and compares this with the profit generated by the current architecture. The decision rule for adopting a new organisational architecture $d_{t+1}^{\prime}$ is given by the inequalities:

$$
\begin{cases}\Pi_{d_{t}}\left(s_{t}\right) \geq E\left[\Pi_{d_{t+1}^{\prime}}\left(s_{t}\right)\right] & \text { reject innovation } \\ \Pi_{d_{t}}\left(s_{t}\right)<E\left[\Pi_{d_{t+1}^{\prime}}\left(s_{t}\right)\right] & \text { accept innovation }\end{cases}
$$

Depending on the management strategy, the firm has a certain propensity to pursue outsourcing such that, given strategy parameter os $(0 \leq o s \leq 1)$, it calculates the expected profits of outsourcing services to other firms, leading to an organisational architecture $d_{t+1}^{\prime \prime}$ with probability $p r_{o s}$

$$
\text { if } \quad p r_{o s}>o s \begin{cases}E\left[\Pi_{d_{t+1}^{\prime \prime}}\left(s_{t}\right)\right] \leq E\left[\Pi_{d_{t+1}^{\prime}}\left(s_{t}\right)\right] & \text { inhouse } \\ E\left[\Pi_{d_{t+1}^{\prime \prime}}\left(s_{t}\right)\right]>E\left[\Pi_{d_{t+1}^{\prime}}\left(s_{t}\right)\right] & \text { outsource }\end{cases}
$$

These are the decision rules the firm follows in order to maximise profitability at each moment in time.

\section{Results}

Using this model, let us consider the relationship between total outsourcing, organisational innovation, and productivity growth in two scenarios. In scenario 1 , new IT technologies have a large impact on internal coordination $\operatorname{costs} \theta_{\text {int }}$. This is the Chandlerian scenario in which early vintages of office technology and IT significantly reduce internal coordination costs while having little or no impact on external coordination costs. In scenario 2, new IT 
technologies have a large impact on external coordination costs $\theta_{\text {ext }}$. This is the internet based IT scenario that we see today. For each scenario, we examine how differential reductions in internal and external coordination costs affect organisational innovation, the sourcing of activities, and long run productivity.

In addition to $\theta_{\text {int }}$ and $\theta_{\text {ext }}$, an important variable in our model is the management's propensity to outsource osp. As discussed in Section 4, this is treated as an exogenous variable. The empirical evidence shows that outsourcing is not part of a long run innovation strategy but is driven by expectations based on consultancy and/or media promises, and by short run cost cutting goals. In the simulations presented here, the propensity to outsource is fixed at an average value (0.5), with an initial division of labour of ten administrative activities. In addition to the propensity to outsource, the decision to outsource is conditional on there being an available supplier who is cheaper than in-house production. At the end of this section we report on sensitivity tests that have been conducted on this parameter and on the initial division of labour.

The parameter values used in the simulations are reported in Table 1 of the Appendix. The results present averages over 200 differently seeded runs. Each run consists of 400 iterations. Sensitivity analysis examines the robustness of results with regards to initial random seedings (Birchenhall et al. 2007). During each iteration, one routine in the technology-characteristics map is drawn randomly, and an innovation strategy is chosen with a probability $\mu_{j, t}$. Performance values for the selected routine are then re-drawn. Furthermore, we initialise the model so that the probabilities for each of the alternative innovation and sourcing strategies are initially the same. In this way one can control for the propensity to outsource osp, and exclude the possibility that differences in initial managerial strategies influence the final outcome. Importantly, this also excludes the possibility that the results are driven by bad management practices. For instance, it is not just badly managed firms that engage in outsourcing. Strategies are selected given a set of technological and transaction costs, and by the firm's past experience of using these strategies.

The set of simulation results generated for scenarios 1 and 2 are presented in Fig. 3. The bold line indicates the mean value for each parameter setting over the 200 scenario 1 runs and over the 200 scenario 2 runs. The thin dashed lines represent the $99 \%$ confidence interval around the mean. Note that the dash-dot-dash lines are the scenario 1 results, i.e. where there are low internal communication costs $\theta_{\text {int }}$ for a given outsourcing propensity of 0.5 . The unbroken lines are the scenario 2 results, i.e. where there are low external communication costs $\theta_{\text {ext }}$ for a given outsourcing propensity of 0.5 . The plots provide information on average productivity, average profits, average unit costs for managerial services, and the extent of the division of labour in the administration of the firm (the depth of hierarchy) for scenarios 1 and 2 .

The first, and most important, observation is that the results reproduce the stylised facts of the outsourcing productivity paradox. The average long term productivity of a firm is lower when it heavily engages in outsourcing, 

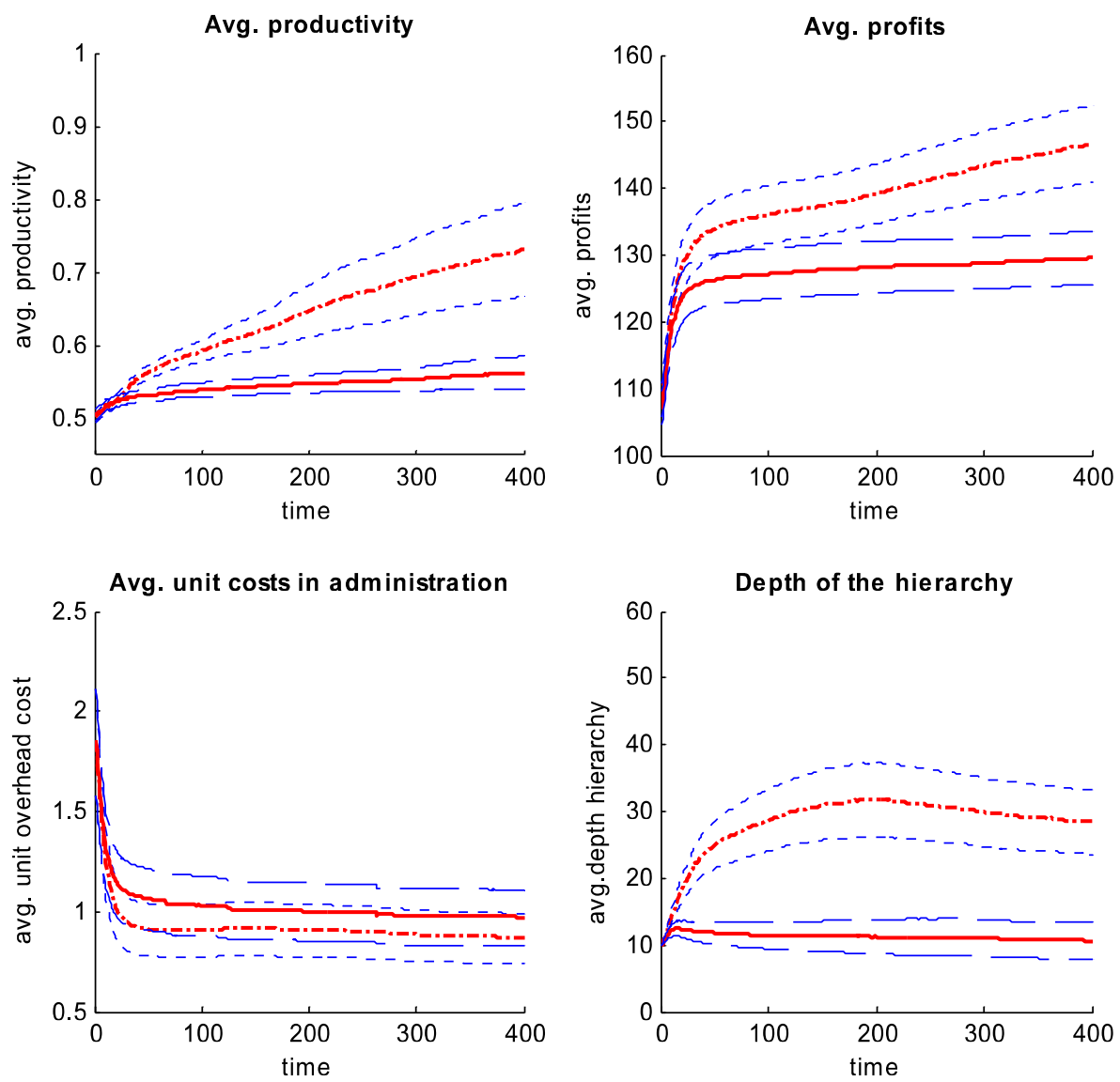

Fig. 3 Simulation results for scenarios 1 and 2

encouraged by an IT technology that significantly reduces external coordination costs. The explanation for the paradox within our model is as follows. The managers of the firm are learning myopically over time, through pure learning-by-doing. That is to say, they do not know the true payoffs to each of the different strategies at the outset. The firm must gather information by observing the payoffs that are generated by past decisions. Under these circumstances, internet ITs make it attractive to engage in outsourcing because they reduce external coordination costs. One consequence of outsourcing is a reduction in the depth of hierarchy. This leads, at least in the beginning, to a reduction in overhead costs. This is the short run cost effect discussed in the empirical literature.

We also see, from Fig. 3, that productivity grows initially. Reinforcement learning means the initial success, in terms of reducing initial costs and gains in productivity, increases the probability that managers will choose the 
outsourcing strategy next time. Each time a chosen strategy increases profits, a higher weight is placed on that option, and a lower weight is placed on each of the alternative options. This sets up path dependency and the potential for lock-in to sub-optional sourcing strategies. For example, if the outsourcing strategy is chosen in the next period, and it again has a positive impact on cutting costs and on raising productivity, this further raises the probability of managers choosing to outsource next time, and so on.

Of course, we have an advantage over the management of the firm in that we can run the model under a number of different scenarios. From Fig. 3, we see that long term productivity growth would be higher if managers choose a non-outsourcing strategy. But the managers cannot 'see' what would happen if they pursue an alternative strategic path. Diminishing returns mean that, as a firm continues along the outsourcing path, productivity growth starts to fall and can even stagnate. The upshot is that managers, focused on the short run cost cutting benefits of outsourcing, succeed in reducing costs but unwittingly reduce the long run innovation potential of the firm as well.

Lower potential productivity growth is due to the total outsourcing relationship. A decision to outsource places an activity/service beyond the control of the outsourcing firm for the remainder of the simulation run. This reduces the number of modular elements that are under the firm's control, restricting its capacity for future organisational innovation and, hence, the probability of identifying a more efficient organisational hierarchy. This directly affects long term productivity growth because long term TFP improvement depends on the ability to engage in the modular reorganisation of value adding in our model.

The results also support the Chandlerian story of the impact of new technology on hierarchal structure - at least for the types and vintages of IT that Chandler is considering in the period between the 1860s and the 1960s. Office and information technologies such calculators, typewriters, Hollerith electric tabulating machines, and book-keeping machines were only applicable to internal administrative activities thus had a significant impact on reducing internal coordination costs and little or no impact on external coordination costs. In the model, these technologies support the development of increased modularity in the administration of the firm. As activities become more specialised, it is easier to improve the quality of managerial services to those valueadding activities. Importantly, the long run potential for radical organisational innovations is exploited successfully. The results of the model indicate that long run productivity under scenario 1 outperforms that under scenario 2 , i.e. of total outsourcing relationships underpinned by internet based ITs.

Taken together, the results accord with the findings of the empirical studies discussed in Section 3. Having said this, one should observe that long run productivity levels when external coordination costs are low are close to the levels that are generated when external coordination costs are high. The outcome depends on the propensity of the firm to invest in radical organisational innovation. This suggests that, where a firm chooses to moderately 
engage in outsourcing, influenced by the impact of IT in external coordination costs, it should scale up its investment in radical organisational innovations, as these enable it to better exploit the long term TFP potential of organisational innovation.

Finally, we report on the sensitivity analysis that has been conducted for the current set of parameter values (see Table 1 of the Appendix). With regards to the managerial propensity to outsource, sensitivity analysis indicates the above set of results hold when the propensity to outsource is greater than 0.2 . When the outsourcing probability is close to zero, the negative effects of total outsourcing become weaker and the results begin to resemble those for scenario 1 . This is because the probability for management to engage in outsourcing is lower and, as a result, organisational modules are retained in house, enabling greater scope for further modular innovation to occur over time.

The sensitivity analysis indicates that the results are also sensitive with respect to the initial division of labour (i.e. the initial degree of modularity) in the firm's hierarchy. With a low initial division of labour, the results are rather similar to those discussed above, but the adjustment process is much slower. In scenario 1, it takes much longer for a minimum division of labour to develop which is sufficient for the recombination potential needed to drive the innovation process. In scenario 2 situations, firms quickly outsource and, as there are very few modules to outsource, productivity and profits are very sluggish from the outset. Hence, the sensitivity analysis confirms the robustness of the results presented in this section.

\section{Conclusions and directions for further research}

The paper has addressed the outsourcing paradox through an investigation of the link between organisational innovation, total outsourcing, and long run productivity growth. The outsourcing paradox is the striking thesis that has emerged from recent empirical research. In order to investigate this paradox, the first part of the paper carefully summarised the empirical findings and identified a set key stylised facts. These stylised facts provide the starting point for an explanation of the paradox. We have highlighted two key factors. The first is the nature of total outsourcing - the predominant form of outsouring relationship - and its impact on the long run potential for organisational innovation. The second key factor that we have highlighted is the role played by new IT sytems. By altering internal and external communication costs, technologies affect both the direction of organisational innovation and the sourcing decision.

In order to explore these key factors we presented a model of organisational innovation that explicitly models the relationship between organisational innovation, total outsourcing, and long run productivity growth. Using this model, we considered the short and long run impacts of outsourcing on organisational 
structure, on costs, and on long term productivity growth for two, alternative IT scenarios.

The findings of the model clearly indicate the conditions under which managers become locked-in to a low productivity growth trajectory. Managers with a high propensity to outsource enjoy early gains in reducing short run costs and are spurred on by the opportunities afforded by internet based IT. Early success in raising profits, through the cutting of short run labour costs and managerial overheads, spurs managers to engage in further outsourcing. Managers in the model are myopic. On the basis of their own experiences, they update information on the perceived payoffs to alternative sourcing strategies. Given positive early experiences, i.e. that choosing to engage in total outsourcing led to a rise in firm profits, a self-reinforcing mechanism is established as managers are more likely to engage in total outsourcing next time.

We know, from running the model under a set of alternative conditions, that managers would enjoy higher long run productivity gains if they retained activities in-house. This is because total outsourcing passes control of outsourced activities to the contractor. The outsourced activities are no longer available for splitting and recombining with other activities into new, more effective organisational modules. Hence, the set of available options for organisational innovation is cut each time management engages in outsourcing. Under total outsourcing there is a real possibility of lock-in to a suboptimal organisational hierarchy, for the firm does not have under its control the set of combinatorial elements that are needed to establish the optimal organisational structure. The findings provides a salutary warning for managers and policy-makers about the potential long term implications of total outsourcing.

Looking forward, there is a need to extend the current analysis. The results depend on a number of conditions. First, outsourcing is purely cost driven and takes the form of a total outsourcing relationship. Potential interactions between suppliers and service firms, as well as the exchange of competences, may exist in other types of outsourcing relationships. In future research we will consider, for instance, the effect of integrated outsourcing relationships on organisational innovation and long run productivity. We expect that this inquiry will further strengthen our argument that it is managerial control of interrelated productive activities that matters, not ownership per se. Another simplification in the current model is the assumption that the extent of the market (demand) is given. Changing demand, for example, may lead to a more complicated set of results over the course of a lifecycle. We will also consider the effect of more competitive supply markets. Different learning environments are also likely to affect the results. Managers may, for example, learn from the experiences of other firms, however imperfectly. Future research will examine the extent to which this affects lock-in to a total outsourcing trajectory. Finally, it is hoped that the current paper will stimulate further research into the outsourcing paradox and raise awareness of this important issue amongst businesses and policymakers. 
Acknowledgements The authors would like to thank Richard Langlois and colleagues at the Economics Department of the University of Connecticut for their insightful comments on an earlier draft of the paper, presented in their seminar series. We are also most grateful to the comments of the two anonymous journal referees. The usual disclaimer applies.

\section{Appendix}

Table 1 Parameter values that are used to calibrate the model

\begin{tabular}{|c|c|}
\hline Variable & Range/value \\
\hline $\begin{array}{l}\text { Efficiency of internal and external coordination } \\
\text { routines }\left\{\theta_{\text {int }}, \theta_{\text {ext }}\right\}\end{array}$ & $\begin{array}{l}\text { Scenario with high external coordination } \\
\text { costs }\{0,2\} \\
\text { Scenario with external coordination costs } \\
\text { lower than internal coordination costs }\{4,2\}\end{array}$ \\
\hline Outsourcing propensity $o s p$ & $o s p=0.5$ \\
\hline Total number of services $F$ & $F=100$ \\
\hline Wage bill $w$ & $W=1$ \\
\hline Performance improvement $\tau$ & $\begin{array}{l}\text { Draw from } N(0.01,0.0025) \text { to initialize firm } \\
\text { parameter, constant over iterations }\end{array}$ \\
\hline Supplier cost advantage $\gamma$ & $\begin{array}{l}\text { Draw from } N(1,0.0625) \text { to initialize firm } \\
\text { parameter, constant over iterations }\end{array}$ \\
\hline Investment propensity $r$ & $\begin{array}{l}\text { For each firm draw from } N(0.02,0.0025) \text {, } \\
\text { constant over iterations }\end{array}$ \\
\hline $\begin{array}{l}\alpha_{\min }, \alpha_{\max } \\
l_{p}\end{array}$ & $\begin{array}{l}\alpha_{\min }=0.01 \alpha_{\max }=1 \\
0.8\end{array}$ \\
\hline$l_{a}$ & $l_{a}=\frac{F}{F+v_{\text {int }}+v_{\mathrm{ext}}}\left(1-l_{p}\right)$ \\
\hline$l_{c}$ & $l_{c}=\frac{v_{i n t}+v_{\mathrm{ext}}}{F+v_{\text {int }}+v_{\mathrm{ext}}}\left(1-l_{p}\right)$ \\
\hline$z$ & $\begin{array}{l}z=\frac{F-\operatorname{Nos}}{F} \\
\text { Nos }=\text { number of outsourced services; } \\
\quad \sum_{\ell} \lambda_{i, \ell}=\text { Nos }\end{array}$ \\
\hline$l_{a, \ell}$ & $l_{a, \ell}=\frac{\lambda_{i, \ell}}{\lambda_{i, \ell}+v_{\text {int }, \ell}+v_{\mathrm{ext}, \ell}}$ \\
\hline$l_{c, \ell}$ & $l_{c, \ell}=\frac{v_{\text {int }, \ell}+v_{\mathrm{ext}, \ell}}{\lambda_{i, \ell}+v_{\text {int }, \ell}+v_{\mathrm{ext}, \ell}}$ \\
\hline $\begin{array}{l}\text { Total consumer income allocated to the firm } \\
\text { in each period Is }\end{array}$ & Is $=100$ \\
\hline Elasticity of demand $\eta$ & $\begin{array}{l}\text { Draw from uniform }[1.05,1.5] \text { to initialise firm } \\
\text { parameter, constant over iterations }\end{array}$ \\
\hline $\begin{array}{l}\text { Initial degree of decomposition of the } \\
\text { techno-organisational architecture } n_{0}\end{array}$ & $n_{0}=10$ \\
\hline Average supplier mark-up $\xi$ & $\begin{array}{l}\text { Draw from uniform }[0,0.5] \text { for each } \\
\text { outsourcing draw }\end{array}$ \\
\hline$\mu_{i, 0}, i=1,2,3$ & $\mu_{1}=\mu_{2}=\mu_{3}=0 . \overline{3}$, at $t=0$ \\
\hline
\end{tabular}

\section{References}

Aghion P, Dewatripont M, Rey P (1994) Renegotiation design with unverifiable information. Econometrica 62:257-282

Altenberg L (1995) Genome growth and the evolution of the genotype-phenotype map. In: Banzhaf W, Eckman FH (eds) Evolution and biocomputation. Springer, Berlin, pp 205-259

Antonelli C (1998) Localized technological change, new information technology and the knowledge-based economy: the European evidence. J Evol Econ 8(2):177-198 
Arthur BW (1991) Designing economic agents that act like human agents: a behavioral approach to bounded rationality. Am Econ Rev 81:353-359

Baldwin CY (2007) Modularity, transactions, and the boundaries of firms: a synthesis. Harvard Business School Working Paper\#08-013. Harvard University, Cambridge, Mass

Baldwin CY, Clark KB (1997) Managing in an age of modularity. Harvard Bus Rev 75(5):84-94

Barras R (1986) Towards a theory of innovation in services. Res Policy 15:161-173

Barthelemy J (2001) The hidden cost of IT outsourcing. MIT Sloan Manag Rev 42(3):60-69

Bengtsson L, von Hartman L (2005) Outsourcing manufacturing and its effect on firm performance. Paper presented at CINet, Brighton 4-6 September 2005

Birchenhall C, Fagiolo G, Windrum P (eds) (2007) Empirical validation of agent-based models. Comput Econ 30(3):189-327 (special issue)

Brock W (1999) Scaling in economics: a reader's guide. Ind Corp Change 8:409-446

Brusoni S, Prencipe A, Pavitt K (2001) Knowledge specialisation, organisational coupling, and the boundaries of the firm: why do firms know more than they make? Adm Sci Q 46: $597-621$

Cane A (2007) Why do so many technology projects end in failure? Financial Times. 'Digital Business: Special Report', 21.11.2007, 2

Chandler AD (1962) Strategy and structure. MIT Press, Cambridge, Mass

Chandler AD (1977) The visible hand: the managerial revolution in American Business. Belknap Harvard University Press, Cambridge, Mass

Chandler AD (1980) The United States: seedbed of managerial capitalism. In: Chandler AD, Daems H (eds) Managerial hierarchies: comparative perspectives on the rise of the modern industrial enterprise. Harvard University Press, Cambridge, Mass

Coase RH (1937) The nature of the firm. Econometrica 4:386-405

Domberger S (1998) The contracting organization: a strategic guide to outsourcing. Oxford University Press, Oxford

Earl M (1996) The risks of outsourcing IT. Sloan Manage Rev 37(3):26-32

Edlin AS, Reichelstein A (1996) Holdups, standard breech remedies, and optimal investment. Am Econ Rev 86(3):478-501

Gallouj F, Weinstein O (1997) Innovation in services. Res Policy 26:537-556

Gianelle C, Tattara G (2007) Manufacturing abroad while making profits at home: a study on Veneto footwear and clothing global value chains. Presented at international workshop on 'internal organisation, cooperative relationships among firms and competitiveness', University of Pisa, 19-20 January, 2007. In: Morroni M (ed) Corporate governance, organisation design and inter-firm relations: theoretical advances and empirical evidence. Edward Elgar (forthcoming)

Görzig B, Stephan A (2002) Outsourcing and firm-level performance. German institute for economic research discussion paper 309

Grossman S, Hart OD (1986) The costs and benefits of ownership: a theory of lateral and vertical integration. J Polit Econ 94:691-719

Harberger AC (1998) A vision of the growth process. Am Econ Rev 88(1):1-32

Hart OD, Moore JD (1988) Incomplete contracts and renegotiation. Econometrica 56:755-785

Hart OD, Moore JD (1999) Foundations of incomplete contracts. Rev Econ Stud 66:115-138

Hinks J, Hanson H (2001) In-house or outsourced? Making the decision. In: Hinks J, Reuvid J (eds) Strategies for outsourcing and facilities management: managing business support service. Kogan Page, London, pp 41-49

Jacobides MG, Winter SG (2005) The co-evolution of capabilities and transaction costs: explaining the institutional structure of production. Strateg Manage J 26:395-413

Kauffman SA, Lobo J, Macready WG (2000) Optimal search on a technology landscape. J Econ Behav Organ 43:141-166

Klein B, Crawford R, Alchian A (1978) Vertical integration, appropriable rents, and the competitive contracting process. J Law Econ 21:297-326

Lacity MC, Hirschheim R (1993) Information systems outsourcing: myths, metaphors, and realities. Wiley, Chichester

Lacity MC, Willcocks LP (1998) An empirical investigation of information technology sourcing practices: lessons from experience. Manage Inf Syst Q 22(3):363-408

Langlois RN (2002) Modularity in technology and organization. J Econ Behav Organ 49:19-37 
Langlois RN (2003a) The vanishing hand: the changing dynamics of industrial capitalism. Ind Corp Change 12(2):351-385

Langlois RN (2003b) Cognitive comparative advantage and the organization of work: lessons from Herbert Simon's vision of the future. J Econ Psychol 24:167-187

Langlois RN, Robertson PL (1995) Firms, markets and economic change. Routledge, London

Leijonhufvud A (1986) Capitalism and the factory system. In: Langlois RN (ed) Economics as a process: essays in the new institutional economics. Cambridge University Press, New York

Loh L, Venkatraman N (1992) Determinants of information technology outsourcing: a cross sectional analysis. J Manage Inf Syst 9(1):7-24

March JG (1991) Exploration and exploitation in organizational learning. Organ Sci 2:71-87

Marengo L, Dosi G (2005) Division of labor, organizational coordination and market mechanisms in collective problem-solving. J Econ Behav Organ 58:303-326

McCarthy JC (2002) 3.3 million US service jobs go offshore, Techstrategy Brief. Forrester Research Inc, Nov 2002

McIvor R (2003) Outsourcing: insights from the telecommunications industry. Supply Chain Manag 8(4):380-394

Miozzo M, Grimshaw DP (2005) Modularity and innovation in knowledge-intensive business services: IT outsourcing in Germany and the UK. Res Policy 34(9):1419-1439

Morgan Chambers (2001) Outsourcing in the FTSE 100. Available at www.cw360.com/ outsourcingreport

Nightingale P, Brady T, Davies A, Hall J (2003) Capacity utilisation revisited: software, control and the growth of large technical systems. Ind Corp Change 12(3):477-517

Nelson R, Winter S (1982) An evolutionary theory of economic change. Belknap Press of Harvard University Press, Boston

Outsourcing Institute (2005) New workplace: outsourcing in Japan. Available at www. outsourcing.com

Overby S (2007) CIO'S exclusive outsourcing and innovation survey. Available at www.cio.com

Polilli S (1989) The "Outsource" strategy; Kodak gambles that IS is better left to others. Software Magazine (October)

Prahalad CK, Hamel G (1990) The core competence of the corporation. Harvard Bus Rev, JulyAugust, 79-91

Preißl B (2000) Service innovation: what makes it different? Empirical evidence from Germany. In: Metcalfe JS, Miles I (eds) Innovation systems in the service economy: measurement and case study. Kluwer, Boston

Prencipe A (1997) Technological competencies and product's evolutionary dynamics: a case study from the aero-engine industry. Res Policy 25:1261-1276

Reinstaller A (2007) The division of labor in the firm: agency, near-decomposability and the Babbage principle. Journal of Institutional Economics 3:293-322

Reinstaller A, Hölzl W (2004) Complementarity constraints and induced innovation: some evidence from the first IT regime. In: Foster J, Hölzl W (eds) Applied evolutionary economics and complex systems. Edward Elgar, Cheltenham, pp 133-514

Reve T (1990) The firm as a nexus of internal and external contracts. In: Aoki M (ed) The firm as a Nexus of treaties. Sage, London

Schilling MA (2000) Toward a general modular systems theory and its application to interfirm product modularity. Acad Manage Rev 25:312-334

Silverberg G, Verspagen B (1994) Collective learning, innovation and growth in a boundedly rational, evolutionary world. J Evol Econ 4:207-226

Simon HA (1996) The architecture of complexity: hierarchical systems. In: Simon HA (ed) The sciences of the artificial. MIT Press, Cambridge, pp 183-216

Simon HA (2002) Near decomposability and the speed of evolution. Ind Corp Change 11:587-599

Smith A (1776) An enquiry into the nature and causes of the wealth of nations. Clarendon, Oxford

Steinmueller WE (2003) The role of technical standards in co-ordinating the division of labour in complex system industries. In: Principe A, Davies A, Hobday M (eds) The business of systems integration. Oxford University Press, Oxford

Sundbo J (1998) The organisation of innovation in services. Edward Elgar, Cheltenham

Tayles M, Drury C (2001) Moving from make/buy to strategic sourcing: the outsource decision process. Long Range Plan 34:605-622 
von Tunzelmann GN (1993) Technological and organizational change in industry during the early industrial revolution. In: O'Brien PK, Quinault R (eds) The industrial revolution and British Society. Cambridge University Press, Cambridge, pp 254-282

Wagner GP, Altenberg L (1996) Perspective: complex adaptations and the evolution of evolvability. Evolution 50:967-976

Weill P, Broadbent M (1998) Leveraging the new IT infrastructure. Harvard Business Press, Boston

Willcocks LP, Lacity MC (2006) Global sourcing of business and IT services: technology, work and globalization. Palgrave Macmillan, Basingstoke

Willcocks LP, Plant R (2003) How corporations e-source: from business technology projects to value networks. Information Systems Frontiers 5(2):175-193

Williamson O (1985) The economic institutions of capitalism: firms, markets, and relational contracting. Free, New York

Yates J (2000) Business use of information and technology during the industrial age. In: Chandler AD, Cortada JW (eds) A nation transformed by information. Oxford University Press, Oxford, pp 107-136

Young AA (1928) Increasing returns and economic progress. Econ J 38:527-542 